\title{
Symmetrization, Mirroring and External Reality: An 'Inner' Perspective
}

\author{
ROSAPIA LAURO GROTTO \\ Department of Health Sciences, Psychology Unit, University of Florence, Italy. \\ Email: rosapia.laurogrotto@unifi.it
}

In the last two decades, mirroring systems have been detected in the monkey and in the human brain. The mirroring mechanisms have been considered as the neural basis for social cognition and interpersonal reactivity, and they have been assumed to support imitation, sharing of emotional states and empathy. Here I would like to compare 'mirroring phenomena' to 'symmetrization phenomena'. In psychoanalytic literature, the construct of symmetrization has been proposed in the context of the Bi-Logic theory by Matte Blanco in 1975, on the basis of clinical evidence obtained in the psychoanalytical setting and following a theoretical analysis derived from the Freudian distinction between Primary and Secondary Processes. I will consider two different types of behaviours, empathic social interactions and the creation of transitional objects and spaces as defined by Winnicott in order to argue that symmetrization, in Matte Blanco's terms, cannot be reduced to mirroring. I will then sketch a hypothesis on the interplay between the symmetric aspects of the mind and external reality in the development of higher relational functions of humans, also taking playing, arts and creativity into account. Finally I will describe the paradigmatic shift in neuro-imaging studies that was introduced with the discovery of the 'Default Mode Network' and its potential relevance in the research on the symmetric and asymmetric aspects of the human mind.

\section{Mirror Systems in the Human Brain and the Embodied Cognition Paradigm}

The cognitive approach is based on the foundational metaphor of the mind as an information processing device; in cognitive neuroscience an information theory approach is adopted in order to explore the computational meaning of the neural activity and therefore derive structure-to-function inferences. By developing a common conceptual framework, many different disciplines could contribute to the progress of cognitive sciences. Following the results obtained by Giacomo Rizzolatti's group in Parma, a large amount of experimental research in the last years has been 
devoted to the exploration and definition of the so-called mirroring systems (Di Pellegrino et al. 1992; Rizzolatti and Craighero 2004) in the animal and human brain. A new scientific approach to cognition has indeed emerged in this domain, the so-called embodied cognition paradigm (Gallese 2001, 2006, 2007). According to this approach, mirroring systems should be seen as potentially relevant to explain very complex phenomena and mental activities, such as first-person knowledge, selfconsciousness and mentalization. Furthermore, mirror neurons are considered to be very good candidates for the role of neural basis of social cognition, although this interpretation has been sometimes criticized (Kosonogov 2012; Heyes 2009), and to support interpersonal reactivity imitation, i.e. the sharing of emotional states and empathy. ${ }^{1}$

The core ability of mirroring systems in the human brain is specifically related to the domain of action recognition: there is empirical evidence that when we watch actions performed by others, we can resort to two different ways of processing them, the crucial difference being the extent to which a given action belongs to one's own motor repertoire. When the observed action is not usually performed by the observer, only declarative knowledge would be available to support recognition; on the contrary, when the action is included in the motor repertoire of the observer, an embodied simulation would take place due to the availability of the mirror system:

According to this hypothesis, 'understanding' is achieved by modelling a behaviour as an action with the help of a motor equivalence between what the others do and what the observer does. The neuroscientific results briefly summarized here seem to point to a crucial role played by action, in virtue of its relational nature, in establishing a meaningful link between agent and observer. (Gallese 2001, 49)

Embodied simulation, that is, mediated by the activation of the mirror system, would allow the subjects to understand 'how it feels' to perform a given action, therefore supporting intentional attunement with the observed agent. According to Gallese (2001), there would be a specific human capability at the basis of social interaction: 'many aspects of our felt capacity to entertain social relationships with other individuals, the ease with which we "mirror" ourselves in the behaviour of others and recognize them as similar to us, they all have a common root: empathy' (Gallese 2001, 42). This view proposes an enlarged account of empathy, which becomes the fundamental function able to support social exchanges and assumes that empathy in itself would be grounded, at the neuronal level, in mirror systems.

\section{A Brief Account on Empathy and the Self-Other Issue from a Philosophical Perspective}

In trying to describe the drift that has modified the use of the term 'Empathy' in the last century and in the current one, I will be guided by the subtle analyses of the issue

1. For a review see Ferrari and Rizzolatti (2014), and for a reconsideration of embodied cognition paradigm see Lauro Grotto (2014). 
provided by Dan Zahavi (2014a) from the Centre for Subjectivity Research at the University of Copenhagen. The term 'Einfühlung' was coined by the German philosopher Robert Vischer in the last decades of the nineteenth century to describe an aesthetic experience, and therefore an experience that involves objects from the material world and not only mind reading. This description of an aesthetic experience was later extended by Theodor Lipps to define the basic capability of understanding others. Eventually, it was translated to the English term 'empathy' by the American psychologist Edward Titchener in 1909.

Zahavi notes that in Lipps' (1909) theory three different domains of knowledge are defined: the knowledge of external objects, originating from perception; the knowledge of oneself, obtained by introspection; and finally the knowledge of others, which is rooted in empathy. With respect to the first two domains, the knowledge of the other is considered to be sui generis and to have an instinctual character. This instinct of empathy involves two components: an instinct directed to imitation and an instinct directed to expression. As reformulated by Zahavi $(2012,222)$ : 'It is the feeling in myself evoked by the expression which is then attributed to the other through projection. It is projected into or onto the other's perceived gesture, thereby allowing for a form of interpersonal understanding'. The projection mechanism is crucial because, according to this view, the only access we have to a psychological experience is our own. A remarkable consequence of this account is that it poses strict limitations on the possibility to recognize something as truly 'new' in the other's mind, to the extent that he or she considers other individuals as 'the product of a projection, a reflection, a radiation of myself - or of what I experience in myself, through the sense perception of an outside physical phenomenon - into this very sensory phenomenon, a peculiar kind of reduplication of myself' (Lipps quoted. in Zahavi 2014b).

Lipps' account of empathy is, in many respects, rather reminiscent of what Gallese (2001) proposed more recently within the context of his Shared Manifold Hypothesis of intersubjectivity, and of the position expressed in the so-called simulation theories (Zahavi 2014a). I remind the reader that the shared manifold is considered by Gallese to be operationalized at three different levels. On the phenomenological level, it is considered as the basis of the universal feeling of being human among humans, that is, the feeling of similarity and common belonging to the same social community that we share with all other human beings. On the functional level, it is characterized in terms of simulation routines. Finally, on the subpersonal level, it refers to a series of mirror-matching mechanisms that operate in a dual mode, namely an expressive and a receptive mode. All three levels seem to be strictly connected to the original proposal by Lipps. As pointed out by Zahavi (2014a, 11), however, Gallese considers the phenomenological approach as the natural philosophical ground of his perspective.

Quite surprisingly, phenomenologists have fiercely contrasted the idea that comprehension of the other should always imply imitation and/or simulation, whether implicit or explicit. They were interested in the definition of the intentional nature 
of the experience we can have of others' mental contents; the point was already clarified by Gurwitsch (1979), and is further discussed in detail by Zahavi (2012).

In this context, I would briefly like to refer to the very critical point of the intentional structure of empathy in Husserl's (1982 [1913]) view. In his general theory of intentional consciousness, Husserl distinguishes between a significative, a pictorial and a perceptual way of intending an object: one can talk about an object that one has never been in contact with, or one can see it in a drawing or picture, or the object can be directly perceived by the subject. It is only in the latter case that the object is given to the subject in its actual presence (in propria persona, as Husserl says). Husserl places the empathic experience within this classification by noting that grasping the other's mind contents will never reach the same degree of immediacy (in Husserl's words 'givenness') that is reached when experiencing something by ourselves or when perceiving an object:

Empathy is unlike perception in that it does not give us its object, the empathized experience, originally. There will always, and by necessity, remain a difference in givenness between that which I am aware of when I empathize with the other, and that which the other is experiencing. Indeed, what distinguishes empathy is precisely that the empathized experience is given as belonging to the other. (Zahavi 2014b)

Overall, the shared manifold hypothesis seems to be more reminiscent of Lipps' than of Husserl's views on empathy in this respect.

\section{Empathy as a Multidimensional Psychological Construct}

In the last three decades, experimental and developmental psychologists have provided substantial contributions that can, to some extent, clarify many of the contradictory aspects of the debate on empathy in philosophy and neuroscience. A large amount of the literature points to the fact that empathy is a multidimensional construct more than a single human capability (Bonino et al. 1998; Miaskiewicz and Monarchi 2008). As a relevant example we will consider the description of the construct that is measured with the most widely used self-report scale of empathy, the Interpersonal Reactivity Index by Davis (1983). The test defines empathy as the reaction of one individual to the observed experience of another, and identifies four factorial dimensions of the scale: 'Fantasy', 'Empathic Concern', 'Personal Distress' and 'Perspective Taking'. The 'Fantasy' dimension taps respondents' tendencies to transpose themselves imaginatively into the feelings and actions of fictitious characters such as those we find in books, movies and plays; 'Empathic Concern' considers 'other-oriented' feelings of sympathy and concern for others that are observed in painful or unpleasant states; 'Personal Distress' measures 'self-oriented' feelings of personal anxiety and unease in tense interpersonal settings and, finally, 'Perspective Taking' estimates the tendency to spontaneously adopt the psychological point of view of others. The sub-dimensions are not statistically independent from each other; as a result, the added up score provides a meaningful assessment of the 
global level of interpersonal reactivity. There is a cluster of three sub-dimensions ('Fantasy', 'Empathic Concern' and 'Personal Distress') that are invariably and more strongly related to each other than to the fourth dimension of 'Perspective Taking'. The latter can be considered as the most sophisticated kind of empathic reaction as it requires the subject to intuit what it is like to be in another's place: it is an experience implying a displacement of the subject, which tries to adopt the perspective of the other; it therefore requires a certain level of knowledge about the characteristics of the other. Perspective-taking is not an immediate, pre-reflexive mechanism like, possibly, those sustained by mirror systems.

Child developmental studies have clearly established that the different forms of empathic reactions mature according to different developmental patterns in early infancy and childhood. Notwithstanding the discrepancies between the account of the empirical evidence provided by various authors already since the 1960s (see, for instance, Eisenberg and Strayer 1987), it is evident that there is a well-established pattern in which the more differentiated empathic capabilities, those that require a full appreciation of the other's experience as belonging to someone else, are the last to develop. The timing of this developmental pattern has shifted towards earlier stages as long as empirical assessment has been able to detect evidence of empathic responses that is not limited to verbal expression. While emotional contagion is already present at birth, 'Empathic Concern' can be clearly detected in children aged around 14-36 months, while 'Perspective Taking' is found to mature at a pre-school age, between 4 and 5 years (for a review of this evidence see McDonald and Messinger 2011).

\section{Back to Representations: Symmetrization as a Bridging Psychoanalytic Concept}

The recent development of formal approaches to psychoanalytic theory, which overcome the distinction between disembodied and embodied cognition (for an introduction to this issue see Lauro Grotto 2014), seems to provide a way to develop a new model of mental processes. This is based on the central idea that it is possible to describe in formal terms the dynamics of representations endowed with affects (see below). The model is based on a topological implementation of the classical Freudian Conscious/Unconscious distinction and on the theory of Bi-Logic mental functioning proposed by Matte Blanco.

In a recent paper (Lauro Grotto 2017), I have argued that psychoanalysis and contemporary cognitive sciences, the latter including both the classic 'cold' approach and the contemporary paradigm of embodied cognition, do indeed share a common focus regarding representation and emotion. What constitutes the most relevant differences between these two disciplines can be summarized in the following two points: (1) according to psychoanalysis, the unifying dimension of affect has a central role in the representational domain, while in the cognitive sciences multiple psychological dimensions are considered in order to describe the emotional content of 
mental life, such as feelings, emotions, sensations and so on; (2) the supposed relationship between the affective and the cognitive components of mental processes is considered along very different - if not opposite - lines in the two approaches.

The construct of affect in contemporary psychoanalytic theory has shifted away from the Freudian core construct of libido: affects emerge from the bodily experience. Such is the case also for emotions, but affects are at odds with emotions, they are not 'all or none' phenomena elicited by specific internal or external stimuli. Rather, affects tend to be more stable in time. According to most contemporary theorists, they also originate within a matrix of interpersonal exchanges: affects are thought to be routed in an inter-subjective space as well as in a bodily experience (Miaskiewicz and Monarchi 2008). Despite the fact that the classical psychoanalytic definition of 'representation endowed with affects' (Freud) seems to suggest that affect can be added to an independent ideational component, in the psychoanalytic view of mental function affect is the primary experience (Freud and Breuer 1912/ 1913; Freud 1923; Bion 1962, 1984): indeed, it is the urge to modulate the blaze of affective experience that amounts to the development of mental representations, as originally proposed in the Freudian theory of the Primary Process and the hallucination of desire (Freud 1900). Contemporary psychoanalysis has made clear that this elaboration is deeply influenced by the dynamics occurring in the interpersonal space (Bion 1984), and 'the process of thinking might be seen as the result of the constant attempt to elaborate affective experiences arising within the interpersonal matrix in representational terms' (Lauro Grotto 2014, 44). It is important to note that this fundamental assumption of psychoanalysis is not a mere descriptive theory of mental function: since Freud's first attempt at describing the features of the affective mind in his Interpretations of Dreams (Freud 1900) the theory was further elaborated by the definition of a set of transformations and features of the mental representations that are typical of the Primary Process: displacement, condensation, absence of temporal ordering and absence of negation. These features were contrasted to the classical logical structure of conscious thinking, so that as early as 1900 psychoanalysis recognized that the consideration of affects in mental life amounts to a radical reorganization of the logical structure of the transformations that mental representations are submitted to.

This point was later reconsidered by the Chilean Analyst, Ignatio Matte Blanco, who developed the first attempt to formalize psychoanalytic theory in logical terms (Matte Blanco 1975, 1998). Matte Blanco described the transformations occurring over the mental representations of the Primary and Secondary Process in terms of two different Logic Systems: while the Secondary Process is assumed to conform to the standard Aristotelian Logic, the Primary Process is recognized as structured upon a new Logic System, namely Symmetric Logic. Symmetric Logic can be derived by integrating into the standard Aristotelian Logic two independent Logical principles, which completely redraw the processes of categorization and the nature of the relationships that can be established among terms in the formal system.

The first principle, known as the generalization principle, states that the Primary Process: 
treats an individual thing (person, object, concept) as if it were a member of element of a set or class which contains other members; it treats this class as a subclass of a more general class, and this more general class as a subclass or subset of a still more general class, and so on. (Matte Blanco 1975, 38)

The consequence of the application of the generalization principle is that when a representation is charged with emotional contents it tends to be perceived not in terms of specific items but in terms of a general a-contextual phenomenon: for example, a visual scene in which I observe a mother who is cheerfully talking to her child is categorized as an instantiation of motherhood, and not in terms of a process that takes place as a sequence of actions performed between two different social actors.

The second principle, known as the symmetry principle, states that the Primary Process 'treats the converse of any relation as identical with the relation. In other words, it treats asymmetrical relations as if they were symmetrical' (Matte Blanco $1975,38)$. When the symmetry principle is applied to the previous example, the mentioned scene is perceived in terms of a relationship between mother and infant that includes only symmetrical links: that is, in Symmetric Logic the differential role of the mother and the child in the parental bond cannot be represented anymore. Again, the two terms are related to each other by a symmetrical relationship implying that 'if $A$ is the mother of $B$, then $B$ is the mother of $A$ ' and meanwhile 'if $B$ is the child of A, then A is the child of B'.

In Symmetric Logic, any chance to represent asymmetric relationships is lost for the following reasons: (1) no ordering criterion can be found in Symmetric Logic; (2) all symmetric relationships between two single items are reformulated in terms of symmetric relationships; therefore, only essentials, such as motherhood, can be represented within Symmetric Logic; and (3) the application of the symmetry principle is that it introduces the equivalence of any proper part of a set to the whole (Matte Blanco 1975). A more intuitive glance at the organization of representation that is imposed by symmetric thinking can be reached by considering that, when the two principles of symmetry and generalization hold, there is a prevalence of similarities over difference: when two representations are found to have a common feature, they become, ipso facto, indistinguishable. Consider the following example derived from clinics: a schizophrenic patient is terribly scared when the door of the room opens because he perceives the door that is opened as indistinguishable from a mouth that is about to bite and devour him.

Note that Symmetric Logic is not confined to pathology (Lauro Grotto and Borozan 2016):Matte Blanco (1975) considers it as profoundly bound to emotional experience. The basic idea is that when a lively emotional experience takes place, the quality of the emotion spreads along all the set of mental representations. So, when we are sad or scared, any mental representation becomes suffused with sadness or fear. The more intense the emotion or the feeling, the more general is this diffusion: when one is in love, one feels that not only the beloved is to be loved but the whole universe. Furthermore, as Dante says in the fifth canto, line 103, of the Inferno (Alighieri 1979, 80): 'Amor, ch'a nullo amato amar perdona' ('Love, which absolves 
no loved one from loving'); that is, no one that is loved can avoid loving back in his or her turn: symmetry, again.

In the last two decades several formal approaches have documented that the Bi-Logic structure proposed by Matte Blanco can be formalized in various ways, such as referring to ultrametric spaces (Khrennikov 1998, 2002, 2007; Lauro Grotto 2008), to quantum logic (Battilotti 2014a, 2014b), and to IT models (Tonti 2014; Murtagh 2012a, 2012b). The application of the two principles in their pure form, and therefore Symmetric Logic in its pure form, completely disrupts the organization of the representational space by producing a unified, hyper-general, homogeneous class. Therefore, Matte Blanco recognizes that the actual formulation of any mental activity should be considered as a mixture of the symmetric and the standard logic, and hence he proposes a Bi-Logic picture of the mind. Accordingly, all mental activities are characterized by a mixture of standard logic and symmetric logic processes. In this account, the presence of affects in mental representation are detectable by the relative prevalence of Symmetric Logic processes over the standard ones (Matte Blanco 1998).

With the term 'Symmetrization', Matte Blanco defines those transformations of mental representations that are achieved under the influence of the Primary Process. Symmetrization is widely present in normal mental activities: in the context of linguistics, for example, it has been considered a possible candidate to instantiate at a logic level the linguistic transformations that ground metaphoric and metonymic representations (Matte Bon 1999). Not only is symmetrization connected to many aspects of psychoanalytic clinics, such as the alterations of language and rationality that are typical of schizophrenic thought (Matte Blanco 1998), but it also was recently related to Behavioural-Cognitive clinics. Maxine Sacks was the first to underline the theoretical relevance of the symmetrization processes as a possible explanation for the cognitive distortions that are described in CognitiveBehavioural Therapy (Sacks 2007): in fact, symmetrization is the only available single construct that can provide a unified view of the ten kinds of alteration of cognition that were described by Beck in 1976 and that still are at the basis of cognitive psychotherapeutic treatments: arbitrary inference, selective abstraction, overgeneralization, magnification and minimization, labelling, personalization, mind reading, emotional reasoning, fortune telling and dichotomous thinking.

The balance between the symmetric and the asymmetric components of Bi-Logic therefore seems to be a crucial warrant of mental equilibrium and a potentially very relevant object of investigation and assessment (Lauro Grotto 2017). Within the recent formal models of $\mathrm{Bi}$-Logic, attempts have been made to quantify the relative balance of asymmetric and symmetric logic in metal representation by providing empirical estimates (Ciaramelli et al. 2006; Lauro Grotto et al. 2007) explored within different contexts of the so-called metric content index. The higher the metric content estimate in a given set of behavioural data, the higher the relative weight of the symmetric component over the asymmetric one in the representational structure that 'expressed' the behavioural data. Within a data analysis approach, Murtagh has recently explored the metric content (see next paragraph) of narratives and 
dialogues in visual scenes. In his research, he tries to connect this quantitative index to the affective experiences that are described in the texts (Murtagh 2013a, 2013b, 2014).

The relationships between the metric content index, empathy and its sub-dimensions of 'Fantasy', 'Empathic Concern', 'Personal Distress' and 'Perspective Taking', was empirically investigated in a correlational study that in a sample of adult subjects contextually evaluated the Interpersonal Reactivity Index (Davis 1983) and compared the results to a quantitative estimate of their metric content index derived from a behavioural test of multiple categorization (Lauro Grotto 2017). The metric content index is a quantitative measure that varies between 0 and 1 ; it provides an estimate of the amount of semantic structure that can be perceived in a set of stimuli: if each element of the set is perceived as unrelated to the other elements the metric content is 0 , while the index increases when similarities can be detected among the elements of the set; the index reaches 1 when the stimuli are perceived as belonging to multiple levels of categories and subcategories. In tune with the psychological theories outlined in the previous paragraph, results showed that lower levels of metric content are associated with higher levels of 'Perspective Taking'. In fact, lower levels of metric content correspond to higher levels of discrimination and separability among mental representations; therefore a lower metric content index is associated with an enhanced ability to discriminate between one's own perspective and the point of view of other people, that is, to higher levels of Perspective Taking. This preliminary empirical evidence suggests that empathic capabilities are connected to a mixture of symmetric and asymmetric processes in the human mind, where a certain degree of asymmetry has always to moderate the symmetric component of thought.

\section{Transitional Phenomena: Symmetrization and External Reality}

Although quantitative models based on ultrametric spaces have been operationalized and are therefore able to support empirical estimates of the metric content of a set of data, at the theoretical level the problem of describing the interaction between the symmetric and the asymmetric components of thought in Bi-Logic is far from trivial. Matte Blanco describes as 'deployment' the process by which a symmetric representation is expanded in a multitude (a potentially infinite multitude) of asymmetric representations (consider, as an example, the infinite single sentences that can be derived by the deployment in asymmetric terms of the symmetric representation of motherhood). The process of symmetrization, however, is in principle less difficult to describe. With the definition of 'bags of symmetry', Matte Blanco describes the presence of nuclei of symmetrized representations in the context of otherwise asymmetric thought. Now, as we have seen, Symmetric Logic has a pervasive and disruptive influence over asymmetric organizations: therefore we need to postulate a mechanism that is able to support, and limit at the same time, the spreading of symmetry along asymmetric representations. 
Based on the analysis of the so-called transitional phenomena (Winnicott 1945, 1971), I would like to suggest the theoretical hypothesis that this problem could be addressed in principle by considering mental processes in relationship to external reality. Winnicott was the first to draw attention to a peculiar and yet absolutely frequent child behaviour, which occurs in the very early phase, when the child, aged one or two, creates a significant and unique emotional bond to an object, often a puppet or a piece of cloth. The child is as reassured by the object as it is by the mother. Furthermore, the object can in itself be 'reassured and calmed' by the child, according to a completely reversible logic. The transitional object is invested with a relational meaning as it stands not only for the absent mother, but also for the child him or herself: the object stands for the self, the other, and the relationship between the two, in a very symmetric way.

Winnicott has described a peculiar rationale in the functioning of the transitional object. It can survive and maintain its function as long as two negative rules are fulfilled: the first rule requires the object to physically exist in order to be 'created', as the manipulation of a real external object is needed in order to instantiate its psychological value and function for the child; the second rule states that it is forbidden to ask who is the one who has created it. The object lives in a specific potential space between fantasy and reality, and any attempt to locate it more precisely on either of the sides would disrupt its function. Asking who is the one who created it would have the same disruptive effect to its functioning as wondering whether Santa Claus really exists. In resemblance to Santa Claus, any transitional object requires social acceptance to fulfil its psychological aims.

Another feature of the transitional object that refers to Symmetric Logic is the fact that the object often shares with the primary object of the child's investment some physical quality, such as the softness or the smell. Apparently the child is creating a hyper-general class of items that smell in a given way, and once the mother and say, the blanket, are perceived to belong to the same class, they become, at some inner psychological level, indistinguishable. This attribution of the quality of another internal, relational and living object to an external, concrete one was defined as 'appersonation' by Gaetano Benedetti (1980) in his study of the psychotherapy of schizophrenic patients.

Although the function of the transitional object per se is restricted to childhood, according to Winnicott more general transitional phenomena do persist in all human activities along the life span, which require the use of external reality in order to express aspects of our inner world. Art, play and culture are recognized by Winnicott as potential spaces. Hence, all aspects of human creativity can be described in terms of transitional phenomena. My hypothesis is therefore that human beings have, at some point, 'learned' to use external reality (both physical and socio-cultural reality) to bend or constrain the symmetric aspects of their inner world to asymmetric ones. In this way external reality is vivified and becomes an animated world.

While the external world is the realm of asymmetry, representations of real objects are also in many respects asymmetric. As for real external objects, here Aristotelian (classical) Logic applies (maybe with the exception of the quantum level). In the realm 
of transitional phenomena, the inner, symmetric aspects of emotions and feeling are therefore constrained and expressed within an asymmetric medium.

\section{Symmetrization and the Default Mode Network}

The Default Mode Network (DMN) is a network of interconnected brain areas that was detected in PET (Positron Emission Tomography, scanning measures of blood flowing into the brain) and fMRI (functional Magnetic Resonance Imaging) experiments by observing a constant and coherent low frequency activation in rest states. The network was recognized as such when its activity had been distinguished from the unstructured background noise activity that the brain at rest was supposed to produce (Raichle et al. 2001, Raichle and Snyder 2007; Northoff et al. 2010; Andrews-Hanna 2012; Raichle 2015). The DMN extends to bilateral and symmetrical cortical areas in the medio-lateral parietal, medial prefrontal, and medio-lateral temporal cortices. As a functional network, the DMN gets activated when the subject is lying undisturbed in the scan, or when he or she is engaged in undirected mental activities, such as mind-wandering, day-dreaming or in thinking about oneself, about his or her own future plans and past recollections. Furthermore, the DMN consistently decreases its activity when the brain is engaged in goal-directed and focused attention tasks, and it has therefore been interpreted as a neural system expressing a kind of 'give or take' dynamics with respect to the system responsible for goal-directed, attention-demanding tasks. In an attempt to combine classical psychodynamic constructs with neurophysiology, DMN has recently been recognized as a possible neurobiological substrate of the psychoanalytical concepts of the Ego and its functioning according to the Freudian psychoanalytic theory (Carhart-Harris and Friston 2010; Buckner et al. 2008; Rizzolatti et al. 2014) and as a relevant structure to assess during psychotherapy (Carhart-Harris et al. 2008; Buchheim et al. 2013).

The DMN has a hierarchic organization that presupposes a large amount of integrative processes. It is therefore a suitable structure to support generalization processes. It would also be interesting to try to assess empirically its function as a hyper-generalization device, as the mechanism required to support the generalization and symmetrization principles of Symmetric Logic in Matte Blanco's term. Furthermore, as the DMN is engaged in a mutual inhibitory interplay with the neural attention systems that are supposed to monitor external reality (Raichle 2015), one could further speculate that the systems that are focused on external reality and the DMN could instantiate at the neural level the two modes of Bi-Logic (Matte Blanco 1975). Along this line of speculation, one should also recognize that, in psychoanalytic terms, the balancing and the integration of the Symmetric and Asymmetric aspects of thinking are primary functions of the mind (Carhart-Harris and Friston 2010).

\section{Some Concluding Remarks}

In the present paper, I have presented two different theoretic concepts, mirroring (Di Pellegrino et al. 1992; Rizzolatti and Craighero 2004; Gallese 2001, 2007, 2006) and 
symmetrization (Matte Blanco 1975, 1998), which are similar in some respects and divergent in others. Mirroring is supposed to be the function of a series of neural systems in the brain, which are considered to be the equivalent of the mirror neurons systems in the monkey's brain. They are considered as the neural counterpart of embodied cognition. Symmetrization is a theoretical concept that was developed in the context of Bi-Logic (Matte Blanco 1975), a logic reformulation of the classical Freudian psychoanalytic theory of the Primary Process (Freud 1900). While mirroring is considered to be a non-representational, pre-reflective activity (Gallese 2001), symmetrization is a mechanism acting over mental representations and it can be described both in a logical (Matte Blanco 1975, 1998; Battilotti 2014a, 2014b) and a topological formalism (Khrennikov 1998, 2002, 2007; Lauro Grotto 2008; Murtagh 2012a, 2012b). Mirror function is essentially a motor simulation function (Di Pellegrino et al. 1992). Its relationship to feelings and empathy is obtained by extending its scope from action perception to the perception of the intentions and mental states of other people via embodied simulation (Gallese 2001).

Symmetry per se has no direct link to empathy and perception of the others' mental state, but it is profoundly linked to the domain of emotion and affects (Lauro Grotto 2017; Matte Blanco 1975, 1998). Symmetrization of mental representations can occur as a consequence of affective activation, irrespective of the origin of the affect or of the emotion, whether primarily in the self or in the other. In this respect, symmetrization is directly linked to the domain in which the use of the term empathy has originally developed, that is, the domain of aesthetics (Zahavi 2012, 2014a).

Both mirroring and symmetrization could support some kind of identification processes: in mirroring, this can take place by mentally simulating the action performed by another as if the observer was performing it by him- or herself (Gallese 2001, 2007, 2006). The distinction between subject and object can be deleted also by symmetrizing it, but this is obtained via a hyper-generalization process in which subject and object are allocated to a unique homogeneous (ultrametric) class and therefore become indistinguishable from each other (Khrennikov 1998, 2002, 2007; Lauro Grotto 2008; Murtagh 2012a, 2012b). Hyper-generalization can occur irrespective of the physical and/or conceptual semantic distance that divides two representations, as we have seen in the domain of transitional phenomena (Winnicott 1945, 1971). Therefore, while for mirror systems the role of the common body scheme and the fact that a given action belongs to the motor repertoire of the subjects are conditions sine qua non for mirroring to occur (Di Pellegrino et al. 1992; Rizzolatti and Craighero 2004; Gallese 2001, 2007, 2006), symmetrization is not bound in any respect to physical similarity since it is a mechanism that inherently disregards differences.

Another relevant point consists of the fact that mirroring mechanisms are considered to be available together with their representational, 'cold', cognitive processes. However, no principled way has - to my knowledge - been found to describe or understand how the 'cold' and the 'hot' components of cognition interact to produce a unified mental state. Bi-Logic is also a dual theory, in which the opposition between Symmetric and Asymmetric Logic was originally very strong. However, 
the current topological re-formalizations of the theory in terms of ultrametric spaces (Khrennikov 1998, 2002, 2007; Lauro Grotto 2008; Murtagh 2012a, 2012b) can be considered as a first step towards the development of the unified Super-Logic which Matte Blanco had foreseen as a system able to overcome the antinomies of Bi-Logic. Other attempts in this same direction are provided by the Quantum Logic formalisms (Battilotti 2014a, 2014b) that were recently developed to formalize Matte Blanco's theory, and also, quite surprisingly, by the effort to reinterpret neuro-imaging results in terms of psychoanalytic Freudian theories (Rizzolatti et al. 2014; Carhart-Harris et al. 2008; Buchheim et al. 2013). Since the discovery of the DMN in the brain, these theories have become more and more popular (Raichle et al. 2001; Raichle and Snyder 2007; Northoff et al. 2010; Andrews-Hanna 2012; Raichle 2015; CarhartHarris and Friston 2010).

Finally, by analysing transitional phenomena, as described by Winnicott (1945, 1971), in terms of Bi-Logic, I have suggested that a possible way to achieve a unified theory of Bi-Logic could be envisaged by considering the interaction of mental representations with external reality as the preferable focus of the theorization.

\section{References}

Alighieri D (1979) La Divina Commedia: Inferno. Florence: Le Monnier.

Andrews-Hanna JR (2012) The brain's default network and its adaptive role in mentation. The Neuroscientist 18, 251-270, https://doi.org/0.1177/1073858411403316.

Benedetti G (1980) Alienazione e Personazione nella Psicoterapia della Malattia Mentale. Turin: Giulio Einaudi.

Battilotti G (2014a) Symmetry vs. duality in logic: an interpretation of bi-logic to model cognitive processes beyond inference. International Journal of Cognitive Informatics and Natural Intelligence 8, 83-97, https://doi.org/10.4018/ ijcini.2014100105.

Battilotti G (2014b) Quantum states as virtual singletons: converting duality into symmetry. International Journal of Theoretical Physics 53, 3488-3502, https:// doi.org/10.1007/s10773-013-1823-9.

Beck AT (1976) Cognitive Therapy and the Emotional Disorders. New York: International Universities Press.

Bion WR (1962) The psycho-analytic study of thinking. International Journal of Psycho-Analysis 43, 306-310, https://doi.org/10.1002/j.2167-4086.2013.00030.x.

Bion WR (1984) Learning from Experience. London: Karnac Books.

Bonino S, Lo Coco A and Tani F (1998) Empatia: I processi di condivisione delle emozioni. Florence: Giunti Editore.

Buchheim A, Labek K, Walter S and Viviani R (2013) A clinical case study of a psychoanalytic psychotherapy monitored with functional neuroimaging. Frontiers in Human Neuroscience, published online 23 October 2013, https://doi.org/10.3389/ fnhum.2013.00677.

Buckner RL, Andrews-Hanna JR and Schacter DL (2008) The brain's default network: anatomy, function, and relevance to disease. Annals of the New York Academy of Sciences 1124, 1-38, https://doi.org/10.1196/annals.1440.011.

Carhart-Harris RL, Mayberg HS, Malizia AL and Nutt D (2008) Mourning and melancholia revised: correspondences between principles of Freudian 
metapsychology and empirical findings in neuropsychiatry. Annals of General Psychiatry 7, 9-32, https://doi.org/10.1186/1744-859X-7-9.

Carhart-Harris RL and Friston KJ (2010) The default-mode, ego-functions and freeenergy: a neurobiological account of Freudian ideas. Brain 133, 1265-1283, https://doi.org/10.1093/brain/awq010.

Ciaramelli E, Lauro Grotto R and Treves A (2006) Dissociating episodic from semantic access mode by mutual information measures: evidence from aging and Alzheimer's disease. Journal of Physiology-Paris 100, 142-153, https://doi. org/10.1016/j.jphysparis.2006.09.008.

Davis MH (1983) Measuring individual differences in empathy: evidence for a multidimensional approach. Journal of Personality and Social Psychology 44, 113-126, http://dx.doi.org/10.1037/0022-3514.44.1.113.

Di Pellegrino G, Fadiga L, Fogassi L, Gallese V and Rizzolatti G (1992) Understanding motor events: a neurophysiological study. Experimental Brain Research 91, 176-180, https://link.springer.com/article/10.1007/BF00230027.

Eisenberg N and Strayer J (eds) (1987) Empathy and its Development. Cambridge: Cambridge University Press.

Ferrari PF and Rizzolatti G (eds) (2014) Mirror Neurons: Fundamental Discoveries, Theoretical Perspectives and Clinical Implications. Philosophical Transactions B, Vol. 369. London: Royal Society Publishing.

Freud S (1900) The Interpretation of Dreams, Standard Edition, Vol. 4-5. London: Hogarth Press, pp. 1-626.

Freud S (1923) Two Encyclopaedia Articles, Standard Edition, Vol. 18. London: Hogarth Press, pp. 235-259.

Freud S and Breuer J (1912/1913) Studies on Hysteria, Standard Edition, Vol. 1. London: Hogarth Press, pp. 1-323.

Gallese V (2001) The 'shared manifold' hypothesis: from mirror neurons to empathy. Journal of Consciousness Studies 8, 33-50, https://philpapers.org/rec/GALTSM.

Gallese V (2006) Intentional attunement: a neurophysiological perspective on social cognition and its disruption in autism. Brain Research 1079, 15-24, https://doi.org/ 10.1016/j.brainres.2006.01.054.

Gallese V (2007) Before and below 'theory of mind': embodied simulation and the neural correlates of social cognition. Philosophical Transactions of the Royal Society B 362, 659-669, https://doi.org/10.1098/rstb.2006.2002.

Gurwitsch A (1979) Human Encounters in the Social World, 2nd edn. Pittsburgh: Duquesne University Press.

Heyes C (2009) Where do mirror neurons come from? Neuroscience and Biobehavioral Reviews 34, 575-583, https://doi.org/10.1016/j.neubiorev.2009.11.007.

Husserl E (1982 [1913]) Ideas Pertaining to a Pure Phenomenology and to a Phenomenological Philosophy - First Book: General Introduction to a Pure Phenomenology. Translated by Kersten F. The Hague: Nijhoff.

Kosonogov V (2012) Why the mirror neurons cannot support action understanding. Neurophysiology 44, 499-502, https://doi.org/10.1007/s11062-012-9327-4.

Khrennikov AY (1998) Human subconscious as a $p$-adic dynamical system. Journal of Theoretical Biology 193, 179-196, https://doi.org/10.1006/jtbi.1997.0604.

Khrennikov AY (2002) Classical and Quantum Mental Models and Freud's Theory of the Unconscious/Conscious Mind. Mathematical Modelling in Physics, Engineering and Cognitive Sciences, Vol. 1. Smaland: Växjö University Press.

Khrennikov AY (2007) Toward an adequate mathematical model of mental space: conscious/unconscious dynamics on $m$-adic trees. Biosystems 90, 656-675, https://doi.org/10.1016/j.biosystems.2007.02.004. 
Lauro Grotto R (2008) The unconscious as an ultrametric set. American Imago 64, 535-543, https://doi.org/10.1353/aim.2008.0009.

Lauro Grotto R (2014) Formal approaches in computational psychoanalysis and the embodiment issue. International Journal of Cognitive Informatics and Natural Intelligence 8, 35-49, https://doi.org/10.4018/ijcini.2014100103.

Lauro Grotto R (2017) Ultrametric spaces in cognitive and psychoanalytic theory: a shared focus on representations and emotion. Quaderni di Matematica 29, 154-178, http://hdl.handle.net/2158/1090703.

Lauro Grotto R and Borozan M (2016) The emotional roots of mental life: a conceptual exploration on the role of emotion in mental space. Oral Communication. International Bi-Logic Conference, London, 26-28 August.

Lauro Grotto $\mathbf{R}$ et al. (2007) Differential impact of brain damage on the access mode to memory representations: an information theoretic approach. European Journal of Neuroscience 26, 2702-2712, https://doi.org/10.1111/j.1460-9568.2007.05881.x.

Lipps T (1909) Leitfaden der Psychologie, 3rd edn. Leipzig: Wilhelm Engelmann.

Matte Blanco I (1975) The Unconscious as Infinite Sets: An Essay in Bi-Logic. London: Karnac Books.

Matte Blanco I (1998) Thinking, Feeling and Being. New York: Routledge.

Matte Bon F (1999) Lingua, analisi della lingua e bi-logica. In Bria P and Oneroso F (eds), L'Inconscio Antinomico: Sviluppi e Prospettive dell'Opera di Matte Blanco. Milan: Franco Angeli, pp. 88-132.

McDonald NM and Messinger DS (2011) The development of empathy: how, when and why. In Acerbi A, Lombo JA and Sanguineti JJ (eds), Free Will, Emotions, and Moral Actions: Philosophy and Neuroscience in Dialogue. Rome: IF-Press, pp. $333-360$.

Miaskiewicz T and Monarchi DE (2008) A review of the literature on the empathy construct using cluster analysis. Communication of the Association for Information Systems 22, 117-142, https://aisel.aisnet.org/cais/vol22/iss1/7.

Murtagh F (2012a) Ultrametric model of mind, I: review. p-Adic Numbers, Ultrametric Analysis and Applications 4, 193-206, https://doi.org/10.1134/ S2070046612030041.

Murtagh F (2012b) Ultrametric model of mind, II: application to text content analysis. p-Adic Numbers, Ultrametric Analysis and Applications 4, 207-221, https:// doi.org/10.1134/S2070046612030053.

Murtagh F (2013a) The new science of complex systems through ultrametric analysis: application to search and discovery, to narrative and to thinking. $p$-Adic Numbers, Ultrametric Analysis and Applications 5, 326-337, https://doi.org/10. 1134/S2070046613040067.

Murtagh F (2013b) Pattern recognition of subconscious underpinnings of cognition using ultrametric topological mapping of thinking and memory. International Journal of Cognitive Informatics and Natural Intelligence 8, 1-16, https://oi. org/10.4018/ijcini.2014100101.

Murtagh F (2014) Mathematical representations of Matte Blanco's bi-logic, based on metric space and ultrametric or hierarchical topology: towards practical application. Language and Psychoanalysis 3, 40-63, http://dx.doi.org/10.7565/ landp.2014.008.

Northoff G, Qin P and Nakao T (2010) Rest-stimulus interaction in the brain: a review. Trends in Neurosciences 33, 277-284, https://doi.org/10.1016/j.tins.2010.02.006.

Raichle ME (2015) The brain's default mode network. Annual Review of Neurosciences 8, 433-447, https://doi.org/10.1146/annurev-neuro-071013-014030. 
Raichle ME and Snyder AZ (2007) A default mode of brain function: a brief history of an evolving idea. NeuroImage 37, https://doi.org/10.1016/j.neuroimage.2007. 02.041 .

Raichle ME, MacLeod AM, Snyder AZ, Powers WJ, Gusnard AD and Shulman GL (2001) A default mode of brain function. Proceedings of the National Academy of Sciences of the United States of America (PNAS) 98, 676-682, https://doi.org/10. 1073/pnas.98.2.676.

Rizzolatti G and Craighero L (2004) The mirror-neuron system. Annual Review of Neurosciences 27, 169-192, https://doi.org/10.1146/annurev.neuro.27.070203. 144230.

Rizzolatti G, Semi AA and Fabbri-Destro M (2014) Linking psychanalysis with neuroscience: the concept of the ego. Neuropsychologia 55, 143-148, https://doi.org/ 10.1016/j.neuropsychologia.2013.10.003.

Sacks M (2007) Bi-logic as a bridge between psychoanalysis and CBT and as a theoretical rationale for Beck's cognitive distortions. British Journal of Psychotherapy 23, 383-394, https://doi.org/10.1111/j.1752-0118.2007.00034.x.

Tonti M (2014) The operationalization of the unconscious: models of subcognitive informatics. International Journal of Cognitive Informatics and Natural Intelligence 8, 17-34, https://doi.org/10.4018/ijcini.2014100102.

Winnicott DW (1945) Primitive emotional development. International Journal of Psycho-Analysis 26, 137-143, https://www.pep-web.org/document.php?id=IJP. 026.0137A.

Winnicott DW (1971) Playing and Reality. London/New York: Routledge.

Zahavi D (2012) Empathy and mirroring: Husserl and Gallese. Life, Subjectivity \& Art: Essays in Honor of Rudolf Bernet 201, 217-254, https://doi.org/10.1007/ 978-94-007-2211-8_9.

Zahavi D (2014a) Self \& Other: Exploring Subjectivity, Empathy, and Shame. Oxford: Oxford University Press.

Zahavi D (2014b) Empathy and other-directed intentionality. Topoi 33, 129-142, https://doi.org/10.1007/s11245-013-9197-4.

\begin{abstract}
About the Author
Rosapia Lauro Grotto is Professor of Dynamic Psychology at Florence University. She graduated in Theoretical Physics in Rome and in Clinical Psychology in Padua, and completed her $\mathrm{PhD}$ in Cognitive Neuroscience at SISSA (Trieste). She is involved in the training programme of the International Psychoanalytic Association. Her research interests are the modelling of psychodynamic intrapsychic and group phenomena and the development of phenomenologic-hermeneutic research methods in the context of health care institutions. Within the context of her research activities, she also contributes to the development of the VirtHuLab (Virtual Human Dynamics Laboratory) at Florence University.
\end{abstract}

